\title{
You are what you eat: market citizens and the right to know about nano foods
}

\author{
Elen Stokes* \\ Lecturer, Cardiff Law School and Associate Member of the ESRC-funded Research Centre for Business, \\ Relationships, Accountability, Sustainability \& Society (BRASS), Cardiff University, UK
}

This article considers the role of consumers in the regulation of nanotechnology. The principal regulatory response to nanotechnology to date has been to require the disclosure of information. One such mechanism currently under negotiation in the food sector is the mandatory labelling of nanomaterial ingredients, commonly justified on the ground that consumers have the right to know what they eat. Not only does this provide a vehicle for free market choice but it also offers one of the few routes to citizen engagement in the policy debate. The potential benefits of nano labelling are substantial. As this article seeks to show, however, the demands placed on nano labelling may be difficult to meet because of a range of limiting factors. By highlighting an expectation-capacity gap, this article points to the need for developing a richer choice environment and for scrutinising difficulties not fully addressed in the policy discourse.

Keywords: choice, information disclosure, nanotechnology, right to know

\section{INTRODUCTION}

Nanomaterials may be small, but they present policymakers with big quandaries. A recurring theme in the policy debate is that nanotechnologies provide a chance to learn from previous scientific controversies, to get things right. ${ }^{1}$ Nano foods are currently under the spotlight but they do not come without regulatory baggage. The past 20 years have brought several high-profile instances in which the policy management of public health risks has been called into question for giving insufficient weight to consumer attitudes and concerns surrounding safety. It is not difficult to recall a number of episodes that have come to represent a general lack of trust in regulatory decision making, particularly in the food sector, which has faced unprecedented challenges. Food scares involving BSE, dioxin contamination, and the increased incidence of food-borne illnesses from Salmonella and E-coli, for example, have meant that consumers today

* I am grateful to Bob Lee, Karen Morrow, Anna Grear and an anonymous referee for their comments. A draft version of this article was presented at the Third Biennial Conference of the European Consortium on Political Research Standing Group on Regulatory Governance, 'Regulation in an Age of Crisis', held at University College, Dublin, June 2010. I thank participants for their insights and suggestions. Any errors or omissions are my own.

1. For discussion on the anticipated opportunities for engagement presented by nano see S Davies, MB Kearnes and M Macnaghten, 'Nanotechnology and Public Engagement: A New Kind of (Social) Science?', in K Kjolberg and F Wickson (eds), Nano Meets Macro: Social Perspectives on Nanoscale Sciences and Technologies (Pan Stanford, Singapore 2010) chapter 19, particularly 406-7. 
are more attuned to safety issues than their predecessors. ${ }^{2}$ Moreover, these episodes reveal a growing scepticism about the ability of the state to regulate potential threats, and in particular its capacity to discern and act in a manner consistent with the public interest. The causes of the confidence crisis are many and do not lie solely in alleged regulatory failure, but one explanation proffered is that the impenetrable and abstruse language of risk marginalises broader social and political considerations. ${ }^{3}$

Stirred into the melting pot recently are new technologies that promise to revolutionise what we eat. New modes of food production face the additional hurdle of unfamiliarity, created in part by an uneasy but widely held perception that 'modern' equates with 'unnatural' whereas more familiar, 'natural' means are societally more palatable. ${ }^{4}$ 'People are understandably sensitive about changes to the food that they eat', ${ }^{5}$ noted a recent House of Lords Committee appointed to review uses of nanotechnologies by the food industry. The overall tone of public attitudes towards new technologies, the Food Standards Agency observes, is 'one of wariness, unease, uncertainty, and sometimes outright negativity'. ${ }^{6}$ The success or failure of technologically advanced foodstuffs is determined by an array of factors relating not only to the safety and integrity of supply chains but also to wider issues of identity, community, ethics and morality making nano foods a political hot potato.

The involvement of civil society is often presented as one way round the perceived 'narrowness' of risk management practices, of bolstering public trust in science ${ }^{7}$ and innovative industries, and of offering a counterbalancing force to the technocracy of regulatory policy. To these ends, public engagement features high on the nanotechnology policy agenda. Since 2004, over 60 such engagement exercises have been conducted in the field of nanotechnologies, mostly in the EU, the US and Australia. ${ }^{8}$ Notwithstanding that such exercises have made valuable inroads into unknowns surrounding public perspectives on the issue, it is important to note that they have emerged sporadically and have been carried out on an ad hoc basis, by a range of different actors and organisations, in different formats, with different purposes and with different foci. ${ }^{9}$

2. G Little, 'BSE and the Regulation of Risk' (2001) 64(5) Modern Law Review 730-56, at 730.

3. For illustration see M Lee, 'Risk and Beyond: EU Regulation of Nanotechnology' (2010) 6 European Law Review 799-821.

4. Nuffield Council on Bioethics, Genetically Modified Crops: The Ethical and Social Issues (Nuffield Council, London 1999) 13-14, especially paragraph 1.40 where it is noted that the natural/unnatural distinction is not one recognised by practising scientists.

5. Science and Technology Committee, Nanotechnologies and Food (HL 2009-10, 22-I).

6. Food Standards Agency, An Evidence Review of Public Attitudes to Emerging Food Technologies (FSA, London 2009) at 6.

7. See eg B Wynne, 'Public Engagement as a Means of Restoring Public Trust in Science? Hitting the Notes but Missing the Music' (2006) 9 Community Genet 211-20.

8. E Stø and others, 'The Future of Deliberative Approaches on Nanotechnology', in R von Schomberg and S Davies (eds), Understanding Public Debate on Nanotechnologies: Options for Framing Public Policy (European Commission, Brussels 2010) chapter 5, at 54.

9. Ibid; also see K Gavelin, R Wilson and R Doubleday, Democratic Technologies? The Final Report of the Nanotechnology Engagement Group (NEG) (Involve, London 2007) particularly 7 which lists the range of UK engagement activities on nano; for initiatives at EU level and in other Member States, eg A Hullmann, European Activities in the Field of Ethical, Legal and Social Aspects (ELSA) and Governance of Nanotechnology (European Commission, Brussels 2008). For calls for a more coherent framework for structured dialogue with civil society see European Economic and Social Committee, 'Opinion on the Communication from the Commission on Regulatory Aspects of Nanomaterials' [2009] OJ C218/21 at paragraph 4.2. 
This article seeks to show that the absence of a coordinated programme of public engagement has shaped and given prominence to a particular 'modality of citizen action ${ }^{10}$; that is, one which plays out through market transactions. The focus here is on proposals currently pending before the EC legislative institutions for the mandatory labelling of nano foods, the rationale for which is anchored to notions that consumers have the 'right to know' about the nanomaterial content of products they buy. The provision of information via labels enables consumers to make free and informed choices, vesting in them the "ultimate power'"1 to realise their goals through effective market participation. Without other, more formal opportunities to exercise agency in relation to concerns about nano foods, purchasing decisions become the only effective way to 'send a message' to the developers and regulators of those products. ${ }^{12}$ Nano labelling, therefore, promotes consumer choice but also - where orthodox channels of participative politics are lacking - consumer voice. The marketplace, by default, offers a forum for consumers in their multiple and sometimes conflicting guises as market players, citizens and participants in everyday life $^{13}$ to mobilise their interests.

Here I argue that the capacity of the nano label to promote decisional autonomy as well as market citizenry is limited by certain features of the choice environment. First, a potential for mismatch can be discerned between the informational objectives of the nano label and its ability to deliver on those goals. A second, related problem is that nano labelling initiatives have emerged without an accompanying choice infrastructure, such as the provision of point-of-purchase information or the guaranteed availability of alternative products. Consequently, whilst nano labelling strategies represent an important first step towards the fulfilment of consumers' rights to know and choose freely between food products, they offer only a partial solution. Moreover, one of the upshots of the policy focus on consumer choice combined with deficiencies in the choice setting is that it forecloses opportunities for broader debates on the social and ethical ramifications of nano-based products. Although information disclosure ensures that industry is directly answerable to consumers and their preferences, nano labelling suffers from a lack of deliberative content, reinforcing risk communication as opposed to meaningful upstream outreach and engagement.

\section{TECHNOLOGIES OF THE TINY}

In 1959, in his address to the American Physical Society, celebrated physicist and Nobel Laureate Richard Feynman posed the following question: 'Why cannot we write the entire 24 volumes of the Encyclopaedia Britannica on the head of a pin?' We can, Feynman argued. By manipulating atoms on a small scale, 'there is no

10. S Jasanoff, Designs on Nature: Science and Democracy in Europe and the United States (Princeton University Press, Princeton 2005) at 120.

11. WH Hutt, Economists and the Public: A Study of Competition and Opinion (Transaction Publishers, New Brunswick 1990) at 257.

12. For a similar account in respect of GM foods, see C Marris and others, Public Perceptions of Agricultural Biotechnologies in Europe: Final Report of the PABE Research Project (Lancaster University, Lancaster 2001) at 70.

13. LA Reisch, 'Principles and Visions of a New Consumer Policy: Discussion Paper by the Scientific Advisory Board for Consumer, Food and Nutrition Policy to the German Federal Ministry of Consumer Protection, Food and Agriculture' (2004) 27(1) Journal of Consumer Policy $1-42$ at 2. 
question that there is enough room on the head of a pin to put all of the Encyclopaedia Britannica'. ${ }^{14}$ Although he used neither the words 'nano' nor 'technology', Feynman is widely credited with the discovery of what we now know as nanotechnology. ${ }^{15}$ 'I would like to describe a field', he noted, 'in which little has been done, but in which an enormous amount can be done in principle'. ${ }^{16}$ More than 50 years on, that potential is beginning to materialise with such far-reaching consequences that Feynman's predictions might now be described as modest. He added:

As soon as I mention this, people tell me about miniaturization, and how far it has progressed today. They tell me about electric motors that are the size of the nail on your small finger. And there is a device on the market, they tell me, by which you can write the Lord's Prayer on the head of a pin. But that's nothing; that's the most primitive, halting step in the direction I intend to discuss. It is a staggeringly small world that is below. In the year 2000, when they look back at this age, they will wonder why it was not until the year 1960 that anybody began seriously to move in this direction. ${ }^{17}$

In the short time since its inception, nanotechnology has become the next 'big thing'. Definitions vary but 'nanotechnology' is commonly used as an umbrella term to describe activities involving the design, production and application of matter (atoms and molecules) at an extremely small scale. Falling under this umbrella is the engineering of nanomaterials; that is, materials with at least one dimension of the order of 1-100 nanometres. The prefix 'nano', from the Greek 'nanos' meaning 'dwarf', is used to denote one billionth of a unit of measurement: a nanometre, therefore, is one billionth of a metre. To put this into perspective, a grain of sand is approximately 1 million nanometres in diameter, a strand of human hair approximately 80,000 nanometres in diameter, and a red blood cell approximately 7,000 nanometres in diameter. Nanomaterials can be naturally occurring (sea spray, for example, contains nanoscale particles, and most viruses are nano-sized), although nanotechnologies now allow us deliberately to manufacture materials with nano dimensions. ${ }^{18}$

Nanotechnologies work on the basis that as a structure or particle reduces in size, its behaviour can change. Some nanomaterials possess unique, often very desirable properties typically not shared by their conventional bulk-scale counterparts. For instance, whereas titanium dioxide and zinc oxide in their conventional forms are opaque, nano versions become transparent. ${ }^{19}$ These novel characteristics have been harnessed across a range of traditional scientific disciplines (including chemistry, engineering, material science, physics, biosciences, medicine and environmental sciences) and exploited in a number of commercial applications. One recent estimate

14. RP Feynman, 'Plenty of Room at the Bottom' presented at the annual meeting of the American Physical Society, 29 December 1959, California Institute of Technology, Pasadena CA. For transcript, see (1992) 1(1) Journal of Microelectromechanical Systems 60-6 at 60.

15. The term 'nanotechnology' was coined by Norio Taniguchi in a paper 'On the Basic Concept of Nano-Technology' (International Conference on Production Engineering, Tokyo, 1974); for other early explorations of nano-scale manufacturing see KE Drexler, Engines of Creation: The Coming Era of Nanotechnology (Anchor Books, New York 1986).

16. Feynman (n 14) at 60.

17. Ibid.

18. Subsequent references to 'nanomaterials' are to the deliberately engineered variety.

19. AD Maynard, 'Nanotechnologies: Overview and Issues', in PP Simeonova, N Opopol and MI Luester (eds), Nanotechnology: Toxicological Issues and Environmental Safety (Springer, Dordrecht 2007) chapter 1 at 4. 
suggests that already there are over 1,000 nano-enhanced consumer products on the market, a figure that has more than quadrupled since $2006 .^{20}$ The most dramatic growth has been in products in the health and fitness sector. Many sunscreens contain nanoscale titanium dioxide or zinc oxide particles because, unlike conventional-scale versions which are opaque, they are transparent as well as extremely effective at absorbing and reflecting ultra-violet (UV) rays. Some skincare products also contain gold nanoparticles for their novel pigmentation: at nanoscale, gold loses its 'gold' colour and becomes red or blue. ${ }^{21}$ A number of products use advanced materials: odourfree socks, for example, will typically have a nanoscale silver coating, renowned for its anti-bacterial and anti-microbial properties. Water-repellent, stain- and creaseresistant fabrics are created by embedding nanoparticles into cotton fibres, producing a durable nano-membrane. Various forms of nanoscale carbon are used to improve the strength and rigidity of tennis racket frames and hard-wearing tennis balls are made with clay nano-composite coatings.

Consumer benefits of nanotechnologies extend to the food sector, too, where a number of applications of this precision engineering are being developed. In its 2010 report, Nanotechnologies and Food, the House of Lords Science and Technology Committee observed that whilst the incidental presence of nanomaterials in foods is not new (for instance, the production of ricotta cheese involves the aggregation of whey particles into nanoparticles), ${ }^{22}$ there is a growing tendency to incorporate nanomaterials specifically because of the changes that occur at this level. There is some ambiguity, the report noted, surrounding the extent to which nanomaterials are being used by the food industry, yet even without concrete data, there is evidence that nano foods are already available and that the market on the whole looks set to expand. ${ }^{23}$ Nanotechnologies offer a variety of possibilities, promising improved food processing, more effective 'functional foods' containing supplements, and enhanced nutrition and flavour. Thanks to nano-capsules, Willy Wonka's fantastical Three Course Dinner Chewing Gum is likely soon to be available on supermarket shelves, allowing for the sequential release of different flavours (but without the unpleasant side-effects suffered by Violet Beauregarde). ${ }^{24}$

Food packaging makes up the largest share of the nano foods market ${ }^{25}$ including 'smart' nano-enforced food contact materials such as nano-clays or nano-films to improve the strength and quality of barriers preventing oxygen absorption and spoilage,

20. See the Project on Emerging Technologies Inventory of Nanotechnology-Based Consumer Products Currently on the Market, available at <http://www.nanotechproject.org/inventories/ consumer/>, last accessed January 2011.

21. For an explanation of the effects of nanoscale on gold, see E Roduner, 'Size Matters: Why Nanomaterials Are Different' (2006) 35 Chemical Society Review 583-92.

22. Science and Technology Committee (n 5) at paragraph 1.4.

23. A report published in 2006 by Cientifica predicts that the market in nano foods grow from $\$ 410$ million in 2006 to $\$ 5.8$ billion in 2012, growth of 1400 per cent in six years, see Cientifica, Nanotechnologies in the Food Industry (Cientifica, London 2006); see also CL Galli, 'The Potential Risks Arising from Nanoscience and Nanotechnologies in Food and Feed Safety' (International Symposium on Nanotechnology in the Food Chain: Opportunities and Risks, Brussels, November 2010).

24. R Gray, 'Willy Wonka Chewing Gum Could Become Reality', The Telegraph (London, 10 October 2010).

25. European Food Safety Authority (EFSA), 'Scientific Opinion of the Scientific Committee on a request from the European Commission on the Potential Risks Arising from Nanoscience and Nanotechnologies on Food and Feed Safety' (2009) 958 The EFSA Journal 1-39 at 1. 
and materials coated with nanoscale silver for its anti-microbial and antifungal effects. Biodegradable nanosensors are capable of monitoring temperature and moisture conditions during storage and transportation, for instance, and antibodies attached to fluorescent nanoparticles can help to detect chemicals or food-borne pathogens. ${ }^{26}$ In agriculture and environmental management, nanotechnologies are being used to develop new tools for the molecular treatment of diseases using, for instance, nanosized agrichemicals to ensure rapid disease detection and to improve the nutrient absorption rates and capacities of plants.

It is precisely this unique 'functionality', however, that has raised concerns about the safety of certain types and applications of materials at nanoscale. ${ }^{27}$ Nanomaterials come in a diverse range of forms and the potential risk they pose to human health or the environment will vary. Some nanomaterials may pose very little threat whereas others may be more hazardous owing to a range of novel properties. The principal concern lies with insoluble, indigestible, non-degradable types of nanomaterials that cannot be broken down in the gut, ${ }^{28}$ particularly where such nanomaterials exhibit a potential to accumulate over time in various organs of the body. ${ }^{29}$ Although persistent nanomaterials are identified as possible causes for concern, data on their long-term effects are limited. Where nanomaterials dissolve or are digested or degraded in the gut, the fact that they are nano-sized becomes irrelevant and toxicity is instead determined by their chemical composition. For other materials, however, size matters. One of the consequences of the small dimensions of nanomaterials is that they become exceptionally mobile, giving them the potential to 'access all areas of the body, even the brain and all areas of the cell, including even the nucleus ... [which] probably makes very small nanoparticles most worrisome to scientists'. ${ }^{30}$ This characteristic has been taken to mean that nanomaterials smaller than 100 nanometres will be taken up by cells through a different pathway from that of larger particles. ${ }^{31}$ A further consequence of their minute size is an increased relative surface area which may result in a corresponding increase in chemical reactivity and hence potential harmfulness (because more surface is available to react per unit mass). As a result of their heightened reactivity, nanomaterials can have what has been described as a 'Trojan horse effect', ${ }^{32}$ where they bond with other (toxic) substances and allow them to cross cellular barriers they could otherwise not pass. The shape of certain nanomaterials may also be an important factor in determining potential risks, for instance, because it has been recognised that carbon nanotubes, as a result of their long, thin, fibrous nature, show some similarities to asbestos. ${ }^{33}$ Finally, the use of certain nanomaterials for their anti-microbial properties (for example, nano silver in food packaging or supplements) may have a harmful effect on the natural flora of the gut. ${ }^{34}$

26. A Grobe, O Renn and A Jaeger, Risk Governance of Nanotechnology Applications in Food and Cosmetics: A Report for the International Risk Governance Council (IRGC, Geneva 2008) at 10.

27. Science and Technology Committee (n 5) at paragraph 4.4 where it notes that 'The small size of nanomaterials may give rise to a risk to human health irrespective of any other novel properties'.

28. Ibid at paragraph 4.6.

29. Ibid.

30. Ibid at paragraph 4.5 .

31. Ibid at paragraph 4.4 .

32. Ibid at paragraph 4.9.

33. Ibid at paragraph 4.10 .

34. Ibid at paragraph 4.11. 
Notwithstanding the many potential advantages of nanotechnologies in the food area as well as the identification of potential risks from certain applications, very little is known about the physiological impacts of nanomaterials, and there are major gaps in knowledge necessary for risk assessment. ${ }^{35}$ Whilst the general risk paradigm (hazard identification and characterisation followed by exposure assessment and risk characterisation) is thought to be appropriate, there are a number of uncertainties related to the applicability of current standard test methods. ${ }^{36}$ Continued reliance on assessment procedures which may be neither validated nor specifically developed for nanomaterials, coupled with persistent and widespread uncertainty surrounding the effects of nanomaterials through their lifecycle, has led to calls for a more targeted research strategy to reduce unknowns and improve evidence-based regulation. Similarly the importance of a sound data base in securing consumer trust and confidence is at the forefront of policy consciousness, given that '[a] major portion of the outcry against nanotechnology results from the continuing promotion of new applications despite critical uncertainties about the extent or severity of various impacts' ${ }^{37}$

Profound uncertainties surrounding metrics and data have led the European Parliament to conclude that current regulations, which were never designed with nanotechnologies in mind, are simply not fit for purpose. Under the existing regulatory framework, novel foods (which would include foods containing nanomaterials) cannot be placed on the market unless they have undergone a safety assessment and are authorised by the European Food Safety Authority. ${ }^{38}$ Only those products considered to be safe for human consumption are authorised for marketing. ${ }^{39}$ The task of determining whether or not a nano food constitutes a 'novel food' and is thus subject to additional assessment and authorisation requirements is assigned to manufacturers or suppliers of those products. Without adequate information and, importantly, without regulatory guidance, there remains the possibility that a nano food will fail to trigger the appropriate regulatory obligations because it was judged by its manufacturer/supplier to be 'substantially equivalent' (ie not 'novel) to a product already on the market with conventional bulk-scale dimensions. Even where a nano food is considered to be novel and hence subject to regulatory control, the European Parliament has remained sharply critical of the applicability of current

35. European Food Safety Authority (EFSA), Draft Scientific Opinion: Guidance on Risk Assessment Concerning Potential Risks Arising from Applications of Nanoscience and Nanotechnologies to Food and Feed, published on 14 January 2011, at page 5; EFSA, Scientific Opinion: The Potential Risks Arising from Nanoscience and Nanotechnologies on Food and Feed Safety, adopted on 10 February 2009, at 6; for an example of data gaps see EFSA, Scientific Opinion: Inability to Assess the Safety of a Silver Hydrosol Added for Nutritional Purposes as a Source of Silver in Food Supplements and the Bioavailability of Silver from this Source Based on the Supporting Dossier Scientific Statement of the Panel on Food Additives and Nutrient Sources Added to Food, adopted on 26 November 2008.

36. European Food Safety Authority, Draft Scientific Opinion (ibid) at 27; see also Food and Agriculture Organization of the United Nations/World Health Organization, Expert Meeting on the Application of Nanotechnologies in the Food and Agriculture Sectors: Potential Food Safety Implications (FAO, Rome 2009) at 46-7.

37. $\mathrm{FAO} / \mathrm{WHO}$ (ibid) at 58.

38. Regulation (EC) No 258/97 on Novel Foods and Novel Food Ingredients [1997] OJ L43/1, Articles 4-7.

39. Ibid, Article 2. 
risk assessment procedures to nanomaterials, ${ }^{40}$ calling for the urgent development of specific and validated methods. ${ }^{41}$

\section{SHIFT TO REGULATION BY DISCLOSURE: 'MAY CONTAIN NANO'}

The epistemic constraints described here have shaped and given prominence to a particular form of policy response to nanotechnologies: information regulation. In relation to foodstuffs, two different approaches to information provision are being pursued. The first, recommended by the House of Lords' Science and Technology Committee, involves the creation of a public register of foods containing nanomaterials. Similar schemes of 'input information regulation', described as such because of the inward flow of information from diffuse sources to a central repository, have been piloted in other nanotechnology policy domains with varying, but on the whole limited, degrees of success. ${ }^{42}$ Moreover, previous schemes of 'nano-reporting' have been developed primarily with regulators in mind, to assist in the design of appropriate regulatory mechanisms, rather than to establish a publicly accessible and searchable database. ${ }^{43}$

The second approach, which provides the focus for the remainder of this article, is product labelling. This example of 'output information regulation' is based on the outward movement of information from single sites to multiple users and a corresponding shift in decision-making responsibilities. Many products containing nanomaterials are already subject to a range of labelling requirements. Yet these requirements make no distinction between bulk- and nanoscale materials; they apply equally to both. For example, EU legislation on the classification, labelling and packaging of chemical substances stipulates that where a substance is classified as hazardous, suppliers shall ensure that the substance is labelled with certain, prescribed information to communicate the hazard to users along the supply chain. ${ }^{44}$ The obligation to label applies to hazardous substances regardless of their structural dimensions: for instance, it applies to nano-lithium in the same way that it would to bulk-lithium. Although existing labelling requirements extend to cover both materials, they make no special provision

40. European Parliament, 'Resolution on the Council Position at first reading for adopting a regulation of the European Parliament and of the Council on novel foods, amending Regulation (EC) No 1331/2008 and repealing Regulation (EC) No 258/97 and Commission Regulation (EC) No 1852/2001', 7 July 2010, P7_TA-PROV(2010)0266, Amendment 23.

41. Ibid, Amendment 120.

42. See eg Department for Environment, Food and Rural Affairs (Defra), UK Voluntary Reporting Scheme for Engineered Nanoscale Materials (Defra, London 2008); for evidence of Government's commitment to improving reporting schemes see HM Government, Response to the RCEP Report 'Novel Materials in the Environment: The Case of Nanotechnology' $(\mathrm{Cm}$ 7620, 2009); examples of reporting schemes in other jurisdictions include the US Environmental Protection Agency 'Nanoscale Materials Stewardship Program', and the Berkeley Municipal Code (amended through Ordinance No 6,960-NS January 2007), Chapter 6.95 of California Health and Safety Code, Title 15.

43. Although note that information submitted under the Defra scheme (above) could be subject to a request for disclosure under the Freedom of Information Act 2000 or the Environmental Information Regulations 2004.

44. Regulation (EC) No 1272/2008 on the Classification, Labelling and Packaging of Substances and Mixtures [2008] OJ L353/1 Title III; see also Commission, 'Classification, Labelling and Packaging of Nanomaterials in CLP and REACH', CA/90/2009 Rev 2, paragraph 2.2. 
for the fact that a material is nanoscale. ${ }^{45}$ Likewise they do not require labels to identify a material as one which derives from or consists of nano.

Amid a growing scepticism concerning the ability of existing regulatory measures to deal with nanotechnologies, a host of new labelling provisions designed specifically for nanomaterials have begun to emerge. Some have been introduced as voluntary standards, ${ }^{46}$ although more significantly others have been implemented through legislation as mandatory market entry requirements. ${ }^{47}$ Proposals for a new Novel Foods Regulation, having reached an advanced stage in the pre-legislative process, include the following requirement: All ingredients present in the form of nanomaterials shall be clearly indicated in the list of ingredients. The names of such ingredients shall be followed by the word 'nano' in brackets. ${ }^{48}$ A virtually identical provision has also been introduced into legislative proposals relating to foodstuffs generally (not just novel foods). ${ }^{49}$ In sectors other than food, nano labelling requirements have already been enacted or are at the pre-legislative stage of the process. ${ }^{50}$ These initiatives are significant not least because labelling has been renounced in other jurisdictions, most notably the US, as an appropriate response to nanomaterials. ${ }^{51}$ Questions

45. Note, however, that where a nanomaterial is thought to be more hazardous than a bulk version of the material for which registration documentation has already been submitted, REACH requires the submission of additional hazard information, Article 22.

46. See, for example, British Standards Institute (BSI), Guidance on the Labelling of Manufactured Nanoparticles and Products Containing Manufactured Nanoparticles, Publicly Available Specification 130 (BSI, London 2007).

47. See Regulation (EC) No 1223/2009 on Cosmetic Products [2009] OJ L342/59, Article 19(1)(g); for background see European Parliament, 'Amendments 30-125: Draft Report on the Proposal for a Regulation of the European Parliament and of the Council on Cosmetic Products (Recast)', 22 September 2009, PE412.251v01-00, Amendments 85, 86 and 87 each introduce nano labelling provisions.

48. European Parliament (n 40) Amendment 75 Article 9(2)(c). Note that at conciliation talks on updating the Novel Foods Regulation the Parliament and the Council were unable to reach agreement, hence the Novel Foods Regulation (EC) No 258/97 will remain in force. One of the points of contention was the proposal for the systematic labelling of ingredients in the form of nanomaterials which, the Council argued, would be excessive particularly in light of the fact that there is already a requirement to consider specific labelling requirements on a case-by-case basis (under Article 9(2) of the proposed recast Regulation; note that Article 8 of the currently applicable Regulation (EC) No 258/97 is broadly comparable). See Council, 'Council position at first reading with a view to adopting a Regulation of the European Parliament and of the Council on novel foods: draft statement of the Council's reasons', 2 March 2010, 11261/09 ADD 1 REV 1 at 12.

49. See Commission, 'Proposal for a Regulation of the European Parliament and of the Council on the Provision of Food Information to Consumers' COM(2008) 40 final; for insertion of nano labelling proposal see Commission, 'Communication on the Functioning of the European Union concerning the position of the Council at first reading on the adoption of a Regulation of the European Parliament and of the Council on the provision of food information to consumers' $\operatorname{COM}(2011) 77$ final at 5 .

50. See Cosmetic Products Regulation (n 47) and European Parliament, 'Report on the proposal for a regulation of the European Parliament and of the Council concerning the placing on the market and use of biocidal products', 1 September 2010, A7-0239/2010, Amendments 183 and 213. 51. See for example Food and Drug Administration (FDA), Nanotechnology: A Report of the US Food and Drug Administration Nanotechnology Task Force (FDA, Rockville 2007) at 34-5, especially 35 where the FDA concludes that 'Because the current science does not support a finding that classes of products with nanoscale materials necessarily present greater safety concerns than classes of products without nanoscale materials, the Task Force does not believe there is a basis for saying that, as a general matter, a product containing nanoscale materials must be labeled as such'. 
of regulation have been a cause of discord between EU institutions, with one MEP commenting that nanomaterials presented 'the biggest stumbling block in the negotiations'. ${ }^{52}$ Within the debate, nano labelling has provided a source of particular contention as intimated by the Council:

The only remaining element for an agreement with Parliament on nanomaterials consists of the labelling thereof in the list of ingredients. A number of delegations hold that this is not useful. A majority of delegations however have indicated a margin of flexibility in the framework for an overall compromise. Parliament attaches a particular importance to this amendment. The Presidency therefore asks for a margin of flexibility with regard to this element. ${ }^{53}$

This tension arose at least in part because, initially, labelling proposals targeted foods produced from nanotechnologies irrespective of their nanomaterial content ${ }^{54}$ calling to mind the process/product distinction that infused much of the debate surrounding the EU's regulation of genetically modified organisms (GMOs).$^{55}$ Policymakers have faced a familiar choice about whether to identify and regulate nano foods on the basis of their composition or underlying production process. Despite early indications that a process-based approach to labelling might be adopted, more recent proposals favour an approach based on the nano composition of the products themselves. But even this approach has come under attack for failing to appreciate differences between foods containing nanomaterials. The Commission, for instance, has warned against systematic nano labelling, arguing that such a measure ought to proceed on a case-by-case basis. ${ }^{56}$ This view is shared by the House of Lords Science and Technology Committee which noted in its report that, while consumers can expect to have access to information about the food they eat, 'blanket labelling of nanomaterials on packages is not, in our view, the right approach to providing information about the application of nanotechnologies' ${ }^{57}$

Elsewhere, outside the EU policy framework, the possibility of nano labelling has been mooted and similarly embroiled in controversy. ${ }^{58}$ In some arenas the issue turns

52. See European Parliament Debate No 15 of 23 March 2009, Eva-Britt Svensson on behalf of the GUE/NGL (European United Left/Nordic Green Left) Group.

53. Council, 'Note from General Secretariat of the Council/Presidency to Committee of Permanent Representatives on the Proposal for a Regulation of the European Parliament and of the Council on Cosmetic Products (Recast)', 3 March 2009, 7014/09 LIMITE, at 3.

54. European Parliament, 'Draft Legislative Resolution on the Proposal for a Regulation of the European Parliament and of the Council on Novel Foods', 18 December 2008, A6-0512/ 2008, Amendment 59, Article 7(2)(c)(2): 'Products produced with the aid of nanotechnologies must be labelled with the words 'produced with the aid of nanotechnologies'.

55. See eg D Winickoff and others, 'Adjudicating the GM Food Wars: Science, Risk, and Democracy in World Trade Law' (2005) 30 Yale Journal of International Law 81-123.

56. European Parliament Debate No 1624 March 2009, Androulla Vassiliou, Member of the Commission; see also Commission, 'Communication on the action taken on opinions and resolutions adopted by Parliament at the March I and II 2009 part-sessions', 4 June 2009, SP(2009)3060. 57. The Committee appears to have grounded its conclusion in arguments that labelling would do little to benefit decision making, and could in fact raise concern and cause confusion. For excerpts from evidence submitted to the inquiry see Science and Technology Committee (n 5) at pages 71-2; see also HM Government, Response to the Lord's Science \& Technology Select Committee Report into Nanotechnologies and Food Nanotechnologies and Food $(\mathrm{Cm} 7857,2010)$ at 17. 58. See eg N Blewett and others, Labelling Logic: Review of Food Labelling Law and Policy, report commissioned by the Australia and New Zealand Food Regulation Ministerial Council (Department of Health and Ageing, Australian Government, Canberra 2011) at 94; also see L Breggin and others, Securing the Promise of Nanotechnologies: Towards Transatlantic Regulatory Cooperation (Chatham House, London 2009) particularly 91-3. 
on whether a product's nano component constitutes 'material information' about the product or the consequences which may result from its prescribed or usual conditions of use. ${ }^{59}$ The US Food and Drug Administration (FDA) concluded in 2007 that there is no scientific basis for requiring that, as a general matter, a product containing nanoscale materials is labelled as such because that information is not material to the product's use. Moreover, the FDA has warned that where information about the use of a product containing nanomaterials is not material, it could be included on a label only if it is not false or misleading; otherwise the product is 'misbranded' and cannot be marketed. It went on to note that since claims regarding the use of nanoscale materials might well be misleading and therefore misbrand a product, manufacturers are advised to consult with the regulators beforehand. Not only is mandatory labelling out of the question under the FDA's jurisdiction, but the prospect of permissible labelling looks bleak too. Whereas initially companies were over-zealous in their use of the term 'nanotechnology' to describe their products or processes in order to attract investment and boost trade (even if they had little or nothing to do with nanotechnology), ${ }^{60}$ nano labels are now fast disappearing not only because of clear policy steers from US Federal regulatory agencies but also because an association with nano may have a negative impact on brand equity.

The potential for a label to mislead or cause anxiety in consumers is outweighed, others argue, by its capacity to propel other policy goals. An independent review of food labelling law and policy in Australia and New Zealand recently urged Food Standards Australia New Zealand (FSANZ) to give nanotechnology high priority because '[i]n the years ahead it is likely to become as contentious an issue in the food supply as gene technology'. ${ }^{61}$ Among other things it recommended that FSANZ and other regulatory bodies 'develop as a matter of urgency a standard for regulating the presence of nanotechnology in the food production chain' which may entail consumer labelling. As noted in one submission of evidence to the review, 'the failure to identify the presence of new tech products or the introduction of a labelling regime that leaves uncertainty as to the presence of such novel ingredients can serve to undermine the credibility of the regulator' ${ }^{62}$ Regulatory control, therefore, serves as an important motivating force for labelling; otherwise 'if the regulator shows hesitancy or uncertainty or is bypassed by events then this will weaken its authority'. ${ }^{63}$ Seen from this perspective, labelling offers a convenient middle ground of policy between the identified need, symbolic or otherwise, for regulatory intervention and concerns about the detrimental impact of intervention on such a fledgling technological sector.

In a similar vein the proposed introduction of nano labelling in the EU is ultimately an uneasy compromise solution, brokered under intense political pressure and only tentatively agreed. Nano labelling is a policy tool in every sense of the term, not only as a device of regulatory policy that will impact upon the behaviour of makers and buyers of nano foods but as an expression of inter-institutional policy tussles

59. FDA (n 51).

60. BJ Feder, 'Concerns That Nanotech Label is Overused' The New York Times (New York, 12 April 2004); for related comments see European Parliament, 'Draft Report on Regulatory Aspects of Nanomaterials', 19 January 2009, 2008/2208(INI) at 5 paragraph F 'companies happily use "nano-claims, as the term "nano" seems to have a positive marketing effect'.

61. Blewett and others (n 58) at paragraph 5.22.

62. Ibid.

63. Ibid. 
between the European Commission, the Council for Ministers and the European Parliament. ${ }^{64}$ The Commission, for example, has long maintained its position that existing regulatory provisions are by and large adequate for dealing with nanomaterials whereas the European Parliament - in particular its Committee on Environment, Public Health and Food Safety (ENVI) - has taken a much more critical stance, which has culminated recently in Members of the European Parliament voting to ban altogether the inclusion of nano-silver and carbon nanotubes in the electrical and electronic products sector. ${ }^{65}$ Of all the regulatory responses to nanotechnologies tabled by ENVI, labelling has provided the path of least resistance; a happy medium between a light touch, deferential approach and calls for regulatory change to account for the novelty of nano. But nano labelling can be seen as an uneasy compromise in other senses too, particularly its capacity to fulfil policy promises to promote consumers' right to know and hence create opportunities for free and informed choice.

\section{RIGHT TO KNOW AND CHOOSE}

Politically, it would be very difficult to maintain a position that information about food products ought not to be provided to consumers. ${ }^{66}$ Indeed, rights to know and to choose are at the core of EU consumer policy. ${ }^{67}$ The Maastricht Treaty recognised for the first time a high level of consumer protection as an EC objective in its own right and was subsequently extended by the Treaty of Amsterdam, which placed an obligation on the Community to promote consumers' right to information as well as protect their health, safety and economic interests. ${ }^{68}$ In instrumental terms, the provision of information has a pivotal role in the shaping of the internal market, since

64. I will explore nano labelling as an inter-institutional policy device in further, later work. 65. European Parliament, 'Report on the proposal for a directive of the European Parliament and of the Council on the restriction of the use of certain hazardous substances in electrical and electronic equipment (recast)', 15 June 2010, A7-0196/2010, Amendment 88, Annex IV. The following justification was offered: 'Nanosilver is already being used as an antimicrobial in EEE [electrical and electronic equipment], e.g. as a coating for mobile phones, or even released by washing machines. Apart from such uses being superfluous, they endanger human health and the environment. Carbon nanotubes may be used in EEE, yet it has been shown that they can have asbestos-like properties. Respected authorities such as the UK Royal Commission on Environmental Pollution, the UK Health and Safety Executive or the German Environment Agency have raised concern about these nanomaterials or even recommended against their use'.

66. For discussion, see E Reid and J Steele, 'Free Trade: What is it Good For? Globalization, Deregulation, and "Public Opinion"” (2009) 36(1) Journal of Law and Society 11-31, 30.

67. European Parliament, 'Resolution on the Commission Communication to the European Parliament, the Council, the Economic and Social Committee and the Committee of the Regions on "Consumer Policy Strategy 2002-2006", P5_TA(2003) 0100 at paragraphs $25-6$ and 29.

68. Treaty on European Union [1992] OJ C191/1, Title XI, Article 129a; Treaty of Amsterdam Amending the Treaty on European Union, the Treaties Establishing the European Communities and Certain Related Acts [1997] OJ C340/173, Article 129a (now enshrined in Treaty on the Functioning of the European Union [2008] OJ C115/47, Title XV, Article 169). Prior to Maastricht, consumer protection was recognised as an autonomous policy aim under the Single European Act [1987] OJ L169/1; however, SEA did not offer a specific legal basis for consumer legislation. 
'[i]nformed and empowered consumers who have effective rights and confidence in them constitute a driving force for economic success and change'. ${ }^{9}$

This right has long been enshrined in EU food regulation which, even in its earliest of legislative measures, emphasised that 'the prince consideration for any rules on the labelling of foodstuffs should be the need to inform and protect the consumer' ${ }^{70}$ This commitment to information provision has been affirmed repeatedly by the EU food strategy, whose spirit and letter reflect the notion that '[p]eople want, and have a right, to know what they are eating'. ${ }^{71}$ Food labelling rules, says the Commission, recognise that right by allowing consumers 'to make choices based on complete information about where food has come from and what it contains' ${ }^{72}$ It is a fundamental principle of those rules that consumers should be 'given all essential information on the composition of the product, the manufacturer, methods of storage and preparation ${ }^{73}$ so that they can make choices 'in full knowledge of the facts' ${ }^{74}$ Likewise the right to know has risen to prominence in the debate on nano foods, having developed from the notion that consumers 'might like to know whether a food has been produced by the use of nanotechnologies" 75 to one where consumers are deemed to have a right to know such information and be able to choose accordingly.

Individual choice is the hallmark of modern consumption. The meaning of consumer society, argues Matthew Hilton, has shifted 'such that the emphasis is no longer on participation for all but on more choice for the individual (that is, for those who can already afford it) ${ }^{76}$ Whereas consumer society was once characterised by access to basic goods, a series of defeats suffered by the consumer activists to a

69. Council, 'Resolution on the Consumer Strategy of the EU (2007-2013)' adopted at its meeting on 30-31 May 2007, at 1; Commission, 'Communication on EU Consumer Policy Strategy 2007-2013' COM(2007) 99 final, see Foreword by Meglena Kuneva, Commissioner for Consumer Affairs.

70. Council Directive (EEC) 79/112 on the approximation of the laws of the Member States relating to the labelling, presentation and advertising of foodstuffs for sale to the ultimate consumer [1979] OJ L33/1, Preamble; Council, 'Resolution on a Preliminary Programme of the European Economic Community for a Consumer Protection and Information Policy' [1975] OJ C92/1 at paragraph 8, 'Attempts have been made to correct the imbalance of power between producers and consumers ... Increasingly detailed information is therefore needed to enable consumers, as far as possible, to make better use of their resources, to have freer choice between the various products or services offered'; see also Council, 'Resolution on the Consumer Dimension of the Information Society' [1999] OJ C23/01; Commission, 'Communication on Consumer Policy Action Plan 1999-2001' COM(98) 696 final; for current legislative commitment see European Parliament and Council Directive (EC) 2000/13 on the approximation of the laws of the Member States relating to the labelling, presentation and advertising of foodstuffs [2000] OJ L109/21 (Food Labelling Directive), Recital 6, and Regulation (EC) No 178/2002 laying down the general principles and requirements of food law, establishing the European Food Safety Authority and laying down procedures in matters of food safety [2002] OJ L31/ 1, Article 16; Regulation (EC) 258/97 on Novel Foods, Article 8.

71. Commission, From Farm to Fork: Safe Food for Europe's Consumers (Office for Official Publications of the European Communities, Luxembourg 2004) at 14.

72. Ibid at 4 and 14 .

73. Ibid at 14 .

74. Food Labelling Directive (n 70), Recital 8.

75. European Parliament (n 54) Amendment 59, emphasis added.

76. M Hilton, 'The Death of a Consumer Society' (2008) 18 Transactions of the Royal Historical Society 211-36 at 215. 
resurgent anti-regulatory movement gave way to a greater focus on choice, the 'watchword of our supposed consumer society today' 77

Such choice is typically defended in terms of its 'welfare enhancing' properties. The primary concern from this perspective is that, without sufficient information, consumers are unable to make choices that correspond with their preferences, giving rise to an inefficient allocation of resources. Allocative inefficiency creates a strong prima facie case for releasing additional information to consumers but the success of this approach rests, not uncontroversially, on the presumption that, equipped with adequate information, consumers will respond in a 'rational' manner; that is, by choosing the best means to his or her ends in order to maximise utility. ${ }^{78}$ If these propositions are correct, the rational-choice model provides a compelling argument for deploying labelling to promote and preserve consumer sovereignty, the notion that, left to their own devices, consumers are the best judges of what is or is not in their individual interests. In its undiluted form, it advances the idea that consumer choice ought to be unrestrained and free from government interference because individual decisions at the point of purchase will replicate full economic rationality at a microeconomic level.

However, the descriptive and predictive power of rational-choice has come under intense attack, leading to not only a gradual relaxation of its precepts and parameters, ${ }^{79}$ but also a more radical excavation and replacement of rational-choice with alternative models of decision making (and hence of free choice). Some of the most fervent criticism has emerged from empirical research in cognitive psychology, ${ }^{80}$ sociology and anthropology ${ }^{81}$ which has been harnessed by law-and-economics scholars in pursuit of a theory of behavioural economics. ${ }^{82}$ These strands of inquiry, although disparate in focus, have been united in challenging the assumptions of 'full rationality'. The basic tenets of consequentialist welfarism and of utility metrics have been attacked on a number of other fronts too, for it transpires that individual 'preferences' are by no means as clear-cut as it may seem. A number of authors have unravelled the model of

77. Ibid at 212.

78. RA Posner, 'Rational Choice, Behavioral Economics, and the Law' (1998) 50(5) Stanford Law Review 1551-75 at 1551.

79. For early criticism and modification of rational maximiser model, see A Marshall, Principles of Economics (9th edn, Macmillan, London 1961); HA Simon, Models of Bounded Rationality: Volume I (MIT Press, Cambridge MA 1982); more recently see RA Posner, Frontiers of Legal Theory (Harvard University Press, Cambridge MA 2001) at 256: 'Individuals are not taken to be hyper rational, emotionless, unsocial, supremely egotistic, omniscient, utterly selfish, non strategic men or women, operating in conditions of costless information acquisition and processing'.

80. For example D Kahneman and A Tversky, 'Prospect Theory: An Analysis of Decision Under Risk' (1979) 47(2) Econometrica 263-91; HA Simon, 'Invariants of Human Behavior' (1990) 41 Annual Review of Psychology 1-19.

81. For example A Wildavsky, 'Choosing Preferences by Constructing Institutions: A Cultural Theory of Preference Formation (1987) 81(1) American Political Science Review 3-22.

82. For discussion see RG Noll and JE Krier, 'Some Implications of Cognitive Psychology for Risk Regulation' (1990) 19 Journal of Legal Studies 747-80; C Jolls, CR Sunstein and R Thaler, 'A Behavioral Approach to Law and Economics' (1998) 50(5) Stanford Law Review 1471-1550; for a defence of rational-choice economics ('which long ago abandoned the model of hyper-rational, emotionless, unsocial, supremely egoistic, nonstrategic man (or woman)') see Posner (n 78) at 1552. 
homo economicus and his self-seeking behaviour, ${ }^{83}$ casting a new and critical light on the distinction traditionally maintained between consumers and citizens. ${ }^{84}$

Growing recognition of the interconnectedness of consumption with citizenship too has a policy outlet, as evidenced by statements that ' $[\mathrm{t}]$ he 493 million EU consumers are central to the three main challenges facing the EU: growth, jobs and the need to re-connect with our citizens' ${ }^{85}$ Consumption is not something to which only the private sphere lays claim. By the same token, choice can be seen not just as an individual matter but as 'an act of allegiance and a protest against the undesired model of society'. ${ }^{86}$ In a particularly vivid account of the permeability of consumption choices to broader social and political issues, the European Commission notes that:

The next three years will see consumer policy coming of age as consumer interests, together with other issues that directly affect ordinary citizens, become increasingly important. The importance of the inter-linkages and overlaps between consumer policy and other policies is set to grow. This coming of age is driven by the political and economic currents running through the EU. It will bring a new influence for consumer policy that will have to be matched by a new maturity on the part of consumers and their representatives. If consumers are to play their role fully as equal stakeholders in society, they need to understand the inter-linkages between their interests and those of others. Their awareness of their rights as stakeholders also demands a greater recognition of their responsibilities to the environment and society at large. ${ }^{87}$

Not only does policy furnish consumers with opportunities to turn to the market to express political, moral or other social concerns, but it also creates an expectation that they will do so, firmly establishing the role of the 'citizen-consumer' ${ }^{88}$ the 'empowered consumer', ${ }^{89}$ or the 'political consumer' ${ }^{90}$ in the machinery of EU governance. ${ }^{91}$ The notion that consumerism offers an avenue of political participation has been explored in the expansive literature documenting a 'turn' both in the rhetoric

83. See A Sen, 'Rational Fools: A Critique of the Behavioural Foundations of Economic Theory' (1977) 6(4) Philosophy and Public Affairs 317-44; A Hirschman, 'Against Parsimony: Three Ways of Complicating Some Categories of Economic Discourse' (1985) 1 Economics and Philosophy 7-21; S Jasanoff, 'Science and Citizenship: A New Synergy' (2004) 31(2) Science and Public Policy 90-94, as well as other papers in that issue, particularly that by R Doubleday. 84. L Cohen, 'Citizen Consumers in the United States in the Century of Mass Consumption', in M Daunton and M Hilton (eds), The Politics of Consumption: Material Culture and Citizenship in Europe and the United States (Berg, Oxford 2001) chapter 10 at 203.

85. Commission, 'Communication on EU Consumer Policy Strategy 2007-2013' (n 69) at 2, emphasis added. Also see 5 for the Commission's key objectives which include empowering EU consumers ('Putting consumers in the driving seat benefits citizens').

86. M Douglas, Thought Styles (Sage, London 1996) at 43.

87. Commission, 'Communication on Consumer Policy Action Plan 1999-2001' (n 70) at 1. 88. M Bevir and F Trentmann, 'Civic Choices: Retrieving Perspectives on Rationality, Consumption, and Citizenship', in K Soper and F Trentmann (eds), Citizenship and Consumption (Palgrave Macmillan, Basingstoke 2007) Part 1 chapter 1; M Everson and C Joerges, 'Consumer Citizenship in Postnational Constellations?', European University Institute Working Papers, Law No 2006/47. 89. Reid and Steele (n 66) at 30.

90. M Scammell, 'Citizen Consumer: Towards a New Marketing of Politics?', in J Corner and D Pels (eds), Media and the Restyling of Politics: Consumerism, Celebrity and Cynicism (Sage, London 2003) chapter 7 at 129.

91. For discussion on the multiple identities of the EU consumer see M Darni, 'Assembling the Fractured European Consumer' (2011) LSE Europe in Question Discussion Paper Series, Paper No. 29/2011; and B Halkier and others, 'Trusting, Complex, Quality Conscious or Unprotected?' (2007) 7(3) Journal of Consumer Culture 379-402. 
and reality of consumption practices. ${ }^{92}$ Consumption, notes Roberta Sassatelli, is undergoing a process of reconfiguration; it is being seen less as a sphere of negative freedom and more as a domain for the exercise of positive freedom. ${ }^{93}$ Through purchasing decisions, citizens 'can always cast their ballot - on a world scale, no less', ${ }^{94}$ an idea explored further by Mary Douglas in an essay on 'shopping as protest':

The consumer wandering round the shops is actualizing a philosophy of life ... Only consider the turning away from pesticides, and the turning away from aerosols, artificial fertilizers and carnivorous diets, and consider the great interest shown in the source of energy, whether powered by nuclear, or by solar, or fossil fuels. These examples of consumer preferences are not responses to market conditions. Quite the contrary, they bid fair to change markets profoundly. ${ }^{95}$

The provision of information is critical to both conceptions of free choice; freedom to choose in the absence of restraints so that preferences are simply unveiled, and freedom to choose in the thicker, more substantive process of deliberation, preference formation and positive action. Whereas the former focuses on the curtailing effects on consumers of a lack of information, the latter emphasises what consumers in receipt of information can choose to do or achieve. ${ }^{96}$ The nature and quality of that information become questions of considerable importance whichever ideological trajectory is adopted, either because it determines the extent to which hurdles of information asymmetries are overcome or because it gives particular shape to resultant means of action.

One issue which has attracted very little attention, but which, however, is central to the nano labelling debate, is the anticipated role of such a provision in the simulation of free choice and hence the discharge of consumers' right to know. In particular, in what ways is nano labelling expected to create opportunities for choice 'in full knowledge of the facts' when 'the facts' are themselves complex, contested and highly uncertain? Notwithstanding the apparent policy consensus that nano labelling will allow consumers to make informed purchasing decisions, there is remarkably little agreement over how such decisions may be aided by the appearance of 'nano' on packaging and what it is exactly that 'nano' is supposed to convey.

\section{CHALLENGES TO CHOICE}

This section offers some tentative reasons why the ability of nano labelling fully to achieve its goals may be limited. The argument here is that, although there is little doubting that some form of nano labelling could be a vital component of the EU's stock of engagement activities, labelling measures alone are insufficient means of communication, outreach and societal dialogue. Labelling initiatives have in the past offered effective routes for the mobilisation of civil society interests by

92. M Micheletti and A Follesdal, 'Shopping for Human Rights' (2007) 30 Journal of Consumer Policy 167-75; R Sassatelli, 'Virtue, Responsibility and Consumer Choice: Framing Critical Consumerism', in J Brewer and F Trentmann (eds), Consuming Cultures, Global Perspectives: Historical Trajectories, Transnational Exchanges (Berg, Oxford 2006) chapter 9.

93. Sassatelli (ibid) at 236.

94. U Beck and E Beck-Gernsheim, Individualization (Sage, London 2002) at 44.

95. Douglas (n 86) at 86.

96. A Sen, 'Freedom of Choice: Concept and Content' (Alfred Marshall Lecture at the Annual Meeting of the European Economic Association, Copenhagen, August 1987) published in the Wider Working Paper Series, Working Paper No 25, at 6. 
non-governmental organisations, if not by collective consumer action, and offers similar potential with respect to nanomaterials. ${ }^{97}$ Yet labelling is inadequate if offered as a complete regulatory response. Broadly speaking, nano labelling measures have been developed in the absence of a concerted approach to engagement and against a backdrop of highly selective and circumspect policymaking. The effectiveness of these measures, as a result, is to some extent impinged upon by its regulatory policy setting in the sense that it demarcates a distinctive 'task' (or 'tasks') for the nano label and governs the strength of its underpinning infrastructure. Within this setting, the capabilities of the nano label and the choice infrastructure have been talked up to the point that an expectation-capacity gap exists. Two examples are offered below. The first limiting factor is that the nano label may fail to fulfil expectations surrounding its role. There is broad agreement that consumers have a right to know, but a right to know what? The second limit relates to the expectation that the application of nano labelling will be aided by other elements of the policy environment, namely the capacity of existing regulations to generate sufficient information on nanomaterials in the supply chain. This assumption, it is argued, is flawed.

\subsection{Right to know what?}

The nano label serves a multitude of purposes. Although these functions are not unrelated, they are sufficiently discrete that nano labelling simultaneously assumes more than one role in conveying information. Its multiple roles place a range of different expectations not only on nano labels and their content, but also on recipients and their capacity to act upon the information disclosed. An initial and exploratory review of the policy documents reveals a number of possibilities. ${ }^{98}$ First and foremost, the nano label serves a basic transparency function, making the invisible visible and contributing to the growing demand for 'see-through science'. ${ }^{99}$ Much of the policy emphasis is on the ability of nano labels to indicate that a product contains or consists of nano matter; 'the contents must always be evident to the consumer so that anyone who wishes to do so is able to choose to avoid foodstuffs containing nanoparticles or nanomaterials'. ${ }^{100}$ It allows for the easy identification of nano-based products so that consumers can distinguish between products of different make-up. ${ }^{101}$

97. See C Ansell, R Maxwell and D Sicurelli, 'Protesting Food: NGOs and Political Mobilisation in Europe', in C Ansell and D Vogel (eds), What's the Beef? The Contested Governance of European Food Safety (MIT Press, Cambridge MA 2006) chapter 5; T Bernauer and E Meins, 'Technological Revolution Meets Policy and the Market: Explaining Cross-National Differences in Agricultural Biotechnology Regulation' (2003) 42(5) European Journal of Political Research 643-83.

98. Policy documents on nano labelling in the food sector (where proposals are currently being negotiated) and the cosmetics sector (where mandatory labelling has already been adopted) were coded and tentative conclusions drawn about the general themes emerging.

99. J Wilsdon and R Willis, See-through Science: Why Public Engagement Needs to Move Upstream (Demos, London 2004).

100. European Parliament Debate No 16 of 24 March 2009, Åsa Westlund on behalf of the PSE Group (Party of European Socialists).

101. Nano products, it could be argued, are 'credence goods', ie goods whose quality is unobservable even after bought and consumed forcing consumers to rely on external sources of information. For discussion on credence qualities see MR Darby and EDI Karni, 'Free Competition and the Optimal Amount of Fraud' (1973) 16(1) Journal of Law and Economics 67-88 especially $68-9$. 
Difficulties may arise, however, in deciphering what the pseudo-scientific descriptor 'nano' on a product label may mean, not only because applications of nanotechnology vary to such a large degree but also because their potential impacts are still subject to persistent and widespread data gaps. The term 'nano' is so ubiquitous, it is argued, that it has become meaningless. Likewise, it is sometimes used to describe processes or substances that fall outside the applicable technical definitions. In spite of its wide usage, the concept of 'nano' does not travel well and may engender a powerful yet unfounded associative effect. Even if definitions are used consistently across different sectors, the potential effects of nano will vary significantly according to the nature of the substance and the exposure scenario. One of the issues raised in the debate is whether the label 'nano' is capable of capturing that diversity.

Description is not itself a value-free exercise; it involves the exercise of discretion and selection, as recent attempts to agree upon a working definition of 'nanomaterial' have shown. ${ }^{102}$ Proposals for the labelling of nano foods define 'nanomaterial' as 'any intentionally produced material that has one or more dimensions of the order of $100 \mathrm{~nm}$ or less', ${ }^{103}$ even though it has been found that there is no scientific evidence to qualify the appropriateness of the 100 nanometre cut-off. ${ }^{104}$ Definitions that use size as the determining criterion have been criticised for being both overinclusive and under-inclusive; uniting these lines of attack is the notion that the adoption of definitions based on size as opposed to function or impact are in danger of being misleading: "whereas physical and chemical properties of materials may change with size, there is no scientific justification for a single upper and lower size limit associated with these changes that can be applied to adequately define all nanomaterials'. 105

102. Scientific Committee on Emerging and Newly Identified Health Risks (SCENIHR), 'Scientific Basis for the Definition of the Term "Nanomaterial", approved on 8 December 2010.

103. European Parliament. 'Legislative resolution of 25 March 2009 on the proposal for a regulation of the European Parliament and of the Council on novel foods; also see Council, 'Position' (EU) No. 6/2010 at first reading with a view to the adoption of a Regulation of the European Parliament and of the Council on novel foods, amending Regulation (EC) No $1331 / 2008$ and repealing Regulation (EC) No 258/97 and Commission Regulation (EC) No 1852/2001' [2010] OJ C122E/38, Article 3(2)(c). The definition of 'engineered nanomaterial' in both of these provisions uses size as the principal determinant (dimensions $\leq 100 \mathrm{~nm}$ ) but it also notes that where a material has dimensions above this threshold, it may nonetheless be deemed to constitute an 'engineered nanomaterial' if it possesses properties typical at the nanoscale, eg properties related to a large relative surface area or specific physico-chemical properties that can be distinguished from those of the same material at conventional scale. In a recent consultation (21 October-19 November 2010) the Commission sought stakeholder views on the development of an overarching definition of 'nanomaterial' for use in any EU communication or legislation addressing nanomaterials. In that process, the Commission's proposed definition still focused solely on size as the key criterion: see Commission, 'Draft Recommendation of $[\ldots]$ on the definition of the term "nanomaterial" C(20..) yyy final, Article 2: Nanomaterial means a material that meets at least one of the following criteria: (i) consists of particles, with one or more external dimensions in the size range $1 \mathrm{~nm}-100 \mathrm{~nm}$ for more than $1 \%$ of their number size distribution; (ii) has internal or surface structures in one or more dimensions in the size range $1 \mathrm{~nm}-100 \mathrm{~nm}$; or (iii) has a specific surface area by volume greater than $60 \mathrm{~m}^{2} / \mathrm{cm}^{3}$, excluding materials consisting of particles with a size lower than $1 \mathrm{~nm}$.

104. SCENIHR (n 103) at 35.

105. Ibid, emphasis added. 
Although the label 'nano' may indeed be a useful indication of nanomaterial content, the extent to which it assists in decision making will be contingent not only on accuracy but also on the meaning that can be extracted from it. Amartya Sen makes the point that '[a] description can be accurate without being a good description. It could be unhelpful, even useless ... Clearly, truth isn't a sufficient condition for a description to be good.' ${ }^{106}$ Concerns over the vacuous nature of 'nano' have led to calls for some qualification of the term; the Council, for instance, has argued for the adaptation of the proposed nano label 'to include a cross reference to the definition of "engineered nanomaterials" and ... to indicate in the list of ingredients that such ingredients are present is acceptable to the Commission'. ${ }^{107}$

Even with such a stipulation, there is evidence in the policy discourse that the nano label's assigned tasks do not necessarily stop at explicitly communicating the nanomaterial content of a product; 'nano' may be expected to carry a number of implicit messages, too. Variations in these messages may arise either from policy documents themselves or from perceptions held by parties outside the confines of formal policymaking, including those held by consumers. As the informational demands on nano labels increase (that is, as it assumes a greater role than simply signalling the inclusion of nanomaterials), so too does the potential for mismatch between what is expected and what may realistically be achieved by printing the word 'nano' on a list of food ingredients. There are suggestions, for example, that the 'nano' label would inform consumers of not only the presence of nanomaterials but also the possibility that the nanomaterials contained in a particular product may have different characteristics, or behave differently, from the same substances in non-nano form. Elsewhere in the policy debate the paucity of information on nanomaterials is emphasised and the prefix 'nano' becomes inextricably linked with uncertainty; likewise references to 'nano' in certain policy quarters have come to be associated with a potential for risk. 'Nano', therefore, may be expected to send multiple messages but those messages are undeniably mixed, especially given the fact that, under the aegis of novel foods regulation, nano foods ought not to appear on the market unless safe. This, suggests David Rejeski, is 'the face of nanotech':

We put together something we call the Tower of Babble which is just a list of what the labels say and it's almost indecipherable ... [O]ne of the things that I want to make sure that I emphasize is this is the face that the public is seeing. The public basically looks at the labels. There's nobody in between the public and their interpretation. There's no scientists, there's no FDA officials, there's no EPA officials. There's nobody. This is the face of nanotech ... I think we did this consumer group with women and we passed these around and they were

106. A Sen, 'Description as Choice' (1980) 32(3) Oxford Economic Papers 353-69 at 353-5. 107. Commission, 'Communication concerning the position of the Council at first reading regarding the adoption of a Regulation of the European Parliament and of the Council on the provision of food to consumers' $\operatorname{COM}(2011) 77$ final at 5; see also Council, 'Working Document from General Secretariat of Council/Presidency to the Working Party on Technical Harmonisation on the Proposal for a Regulation of the European Parliament and of the Council on Cosmetic Products (Recast)', 26 February 2009, 6972/09 LIMITE at 74 where it notes that in relation to nano labelling proposals 'Some delegations express doubts on added value of this provision. DE propose clarification "whenever these change the characteristics of the product"; for a similar argument but one which favours a more inclusive definition see European Parliament (n 60) Explanatory Statement at 7, 'nanotechnology also covers a functional change in the properties of a material owing to its small size where the particles are larger than $100 \mathrm{~nm}$ '. 
totally confused ... [W] hat does it mean that nanotechs are in there? What are these claims, both the benefits and the risks? So there is an incredible amount of confusion there. ${ }^{108}$

This illustrates the possibility that an expectation-capacity gap may open from the opposite direction, where there is an expectation on the part of consumers that the label 'nano' is communicating more than, or something different from, that which is intended. One of the concerns here is that, even if a label is designed to communicate the presence of a material whose dimensions satisfy the size criteria prescribed, it may nonetheless be interpreted as a sign of hazardousness. A number of policy actors have been keen to stress that 'nano' neither implies a specific risk nor does it necessarily mean that the material in question actually has new hazard properties compared to its bulk-scale counterpart. ${ }^{109}$ There remains the possibility, however, that "the general mention on labels of nano-scale materials in cosmetic products using the term "nano" might be misunderstood by consumers as a warning, ${ }^{110}$ notwithstanding the fact that this is not, according to the legislative institutions, the policy aim. ${ }^{111}$

\subsection{Limited choice infrastructure}

The second potential limit on choice may stem from the choice environment in which nano labelling is implemented. The focus here is on the external logics of choice, because 'freedom to perform an act is meaningless unless the subject is in possession of the requisite means of action'. ${ }^{112}$ This argument reflects the idea that 'choice' connotes more than what a consumer is faced with (the act of choosing); it refers to what a consumer is presented with too (the choice situation). In this sense the label 'nano' goes only part of the way towards offering tangible opportunities for free and informed decision making; what is missing is an adequate choice infrastructure on which labelling measures can rest.

Arguably the most significant limit to genuine choice, in either its procedural or substantive sense, in this context stems from a lack of information on nanomaterials. This can be seen to play out in different ways, manifesting itself not only in gaps in the risk assessment and management of certain food-related uses of nano but also in a scarcity of readily available information at the point of sale. ${ }^{113}$ Closely linked with this is the low level of consumer awareness of nanomaterials, their uses, potentially desirable and/or hazardous effects. The Rapporteur responsible for steering proposals for a recast Novel Foods Regulation (which includes provisions on mandatory nano labelling) through the legislative process underlines the plausibility and prevalence of the awareness gap: 'Let me deal with nanotechnology first. I had absolutely no idea

108. D Rejeski, Food and Drug Administration Nanotechnology Task Force Public Meeting on Nanotechnology Materials in FDA Regulation Products, 10 October 2006, transcript, available at <http://www.fda.gov/ScienceResearch/SpecialTopics/Nanotechnology/Nanotechnology TaskForce/ucm111425.htm> accessed 22 December 2010.

109. SCENIHR (n 103) at 31.

110. Council, 'Addendum to "I/A" Item Note', 17 November 2009, 12682/09 ADD 1 REV 1, at 2. 111. European Parliament Debate No 15 of 23 March 2009, Dagmar Roth-Behrendt, Rapporteur.

112. FH Knight, Freedom and Reform: Essays in Economics and Social Philosophy (1982) 7 , as cited in Sen (n 96).

113. Nuffield Council on Bioethics (n 4) at paragraph 5.43. 
what it was. I think that lots of consumers are in the same position' ${ }^{114}$ Empirical evidence to date supports this contention, ${ }^{115}$ with one of the most stark results emerging from a US survey which found that $95 \%$ of respondents had 'heard almost nothing or a little about nanotechnology'. ${ }^{116}$ Not unreasonably, this may lead us to question whether the simple provision of information can have any discernible effect on either purchasing choices or consumer awareness. ${ }^{117}$ On the latter point, it is sometimes argued that nano labelling will, over time, result in an improved consumer knowledge base and serve as a springboard for more elaborate engagement activities by stimulating demand for further information. This snowball effect can be charted in relation to other new technologies, although in respect of nanotechnologies there has been particular emphasis on the need for orchestrated information and engagement initiatives sooner rather than later:

Given that nanoprocesses take place in nanoscopic dimensions $\left(10^{-9}\right)$, which are hard for the uninitiated to imagine, nanomaterials require, from the outset, constructive dialogue with consumers so as to identify and avoid dangers and to allay unfounded fears that may arise. ${ }^{118}$

Low levels of consumer awareness can also be attributed to problems existing in the fabric of regulations applicable to nanotechnologies. The principal concern here is with the limited capacity of existing regulatory provisions to detect and monitor nanomaterials along the supply chain, which in turn lessens the chances that a manufacturer will be privy to information regarding the nano components of substances he or she buys and incorporates into final products intended for consumer use. The regulation of chemicals up and down the supply chain is, until the moment they are included in foodstuffs, governed by the REACH (Registration, Evaluation, Authorisation and Restriction of Chemical Substances) Regulation. ${ }^{19}$ Although it is argued (particularly by the Commission) that the information disclosure requirements under $\mathrm{REACH}$ are in principle triggered by substances with nano dimensions, the capacity of REACH in practice to elicit information on nano substances has been questioned. ${ }^{120}$ One of the fundamental concerns is that nano substances produced in

114. European Parliament Debate No 16 of 24 March 2009, Kartika Tamara Liotard, Rapporteur.

115. Commission, 'Communicating Nanotechnology: Why, to Whom, Saying What and How?'(DG for Research, Brussels 2010) at 22.

116. J Macoubrie, 'Nanotechnology: Public Concerns, Reasoning and Trust in Government' (2006) 15(2) Public Understanding of Science 221-41 at 232.

117. For a critique of information provision impact on perception see DM Kahan and others, 'Cultural Cognition of the Risks and Benefits of Nanotechnology' (2009) 4(2) Nature Nanotechnology 87-90.

118. European Economic and Social Committee, 'Opinion on the Communication from Commission on Regulatory Aspects of Nanomaterials' [2009] OJ C218/21 at paragraph 2.12, emphasis added.

119. Regulation (EC) No 1907/2006 [2006] OJ L396/1. The incorporation of chemical substances in foods is excluded from REACH requirements, Article 2(5)(b).

120. E Stokes, 'Regulating Nanotechnologies: Sizing Up the Options' (2009) 29(2) Legal Studies 281-304, 286; for a fuller exposition see RG Lee and S Vaughan, 'REACHing Down: Nanomaterials and Chemical Safety in the European Union' (2010) 2(2) Law, Innovation and Technology 193-217; Royal Commission on Environmental Pollution (RCEP), Novel Materials in the Environment: The Case of Nanotechnology (The Stationery Office, Norwich 2008) chapter 4. 
small volumes will fail to meet the one tonne per annum threshold, thus escaping registration (and hence information disclosure) obligations. Even if the tonnage threshold has been met, it is far from clear that risk assessment methods used to generate data for registration and disclosure are suitable for substances at nanoscale. Moreover, it is highly unlikely that downstream users of nano substances (such as a manufacturer of food products) will have any contractual right to ask for information about those substances. The upshot is that a manufacturer of a food product may unknowingly market a nano food product which should be labelled as such. The prospect of nano food products entering the market without an accompanying label raises the additional point that, as well as adequate information, genuine and effective choice depends on the availability of alternatives to nano products. Put another way, meaningful choice relies on the fact that products not carrying the label 'nano' are indeed nano-free. This expectation cannot, it seems, be fulfilled by current regulations, whose principal focus is on conventional-size substances.

\section{CONCLUDING REMARKS}

There is a certain inevitability about nano labelling. In many respects it offers the most obvious regulatory route; until more is known about the behaviour and impact of nanomaterials, and in the absence of concrete evidence that their use is likely to lead to unacceptably serious losses, it is inevitable that legislatures will be reluctant to incur potentially significant expenditure on the introduction of more restrictive measures. It also resonates strongly with the EU's ever-growing commitment to the consumer. Emerging at a confluence point between scientific uncertainty and consumer protection, nano labelling provides but one means of generating much needed information about the nano foods industry.

The provision of such information is typically justified on the ground that consumers have a right to know about what they eat which, in turn, forms a foundation for their right freely to choose between materially different products. Choice may be an exercise in bare liberty or it may entail more reflective habits of deliberation, engagement and the mobilisation of interests off the cardinal scale of economic rationality. In the latter sense, and without particularly prominent or widespread outreach activities, the supermarket begins to look more like an arena for quasi-participation.

This article has sought to show that although the label 'nano' may simulate free choice in its thinnest sense, that is, ensure the freedom to choose between nano and non-nano foods without intervention or coercion, a number of factors may serve to undermine the extent to which consumers' purchasing choices are an expression of agency. These factors arise because of a discernible discord between expectations and capacities of nano labels, their intended users and the policy infrastructure that gives shape and meaning to the exercise of choice. Along with a centrifugal movement of information to consumers comes a centrifugal movement in decisionmaking responsibilities, although the critical question here is whether those responsibilities are adequately supported. Without a bright line definition of 'nanomaterial' and in the face of huge data gaps, the nano label cannot realistically be tasked with anything other than alerting consumers to the sheer uncertainty. In light of predictions that these gaps will persist and may grow to become even more pronounced as nanotechnologies continue to open doors to new possibilities, informing consumers of uncertainties is surely a worthwhile exercise in itself. But even this is a tall order because of the complexities afflicting the area. The potential benefits of nano 
200 Journal of Human Rights and the Environment, Vol. 2 No. 2

labelling, in terms of improved information flows, transparency and opportunities for better purchasing decisions are substantial, regardless of whether consumers act as individuals or are galvanised into collective civic action. Yet without a richer, more effective choice infrastructure enabling decisions to be made in a meaningful context, the value of nano labelling is ultimately a matter of chance, not of choice. 